\title{
Unexpected Reactivation of Herpes Simplex Virus as Keratitis during Chemotherapy
}

\author{
Michelle Gainty ${ }^{*}$, Justin $\mathrm{PaO}^{2}$, Aaron Farmer ${ }^{3}$ and Jasmine Han ${ }^{4}$ \\ ${ }^{1}$ Residency Program, Womack Army Medical Center in Fort Bragg, USA \\ ${ }^{2}$ Chief of Optometry Clinic, Lyster Army Health Clinic in Rucker, USA \\ ${ }^{3}$ Infectious Disease Service, Womack Army Medical Center in Fort Bragg, USA \\ ${ }^{4}$ Gynecology Oncology, Madigan Army Medical Center in Tacoma, USA
}

Submission: September 26, 2017; Published: October 25, 2017

*Corresponding author: Michelle Gainty, DO, CPT, OBGYN Residency Program, Womack Army Medical Center in Fort Bragg, 816 Sumner Drive Apt 29, Fayetteville, NC 28310, USA, Tel: 410-980-7741; Email: Michelle.L.Gainty.mil@mail.mil

\section{Abstract}

Background: Herpes Simplex Virus Type (HSV) affects $>90 \%$ of the adult population of the United States. Eye involvement can result in progressive scarring and permanent visual impairment.

Case: An 81 years old female with a high grade ovarian adenocarcinoma underwent one cycle of chemotherapy before complaining of left red eye and tearing not relieved with olopatadine hydrochloride eye drops. Prompt optometry consult led to diagnosis of herpetic keratitis. She was given ganciclovir ophthalmic gel and oral valacyclovir with complete resolution of symptoms and impaired visual acuity. To date, this patient has normal vision with mild transparent stromal corneal scarring.

Conclusion: Herpetic keratitis can have significant consequences including permanent corneal scarring, damage of nerves, and vision loss. Early diagnosis and prompt treatment are required to prevent serious long-lasting sequelae.

\section{Introduction}

Herpes Simplex Virus (HSV) infects $>90 \%$ of the adult population of the United States. The estimated prevalence of herpetic keratitis is 150 in 100,000 in the United States. HSV lesions can recur throughout life and have been known to affect liver, lung, genitalia, eye, and central nervous system. When affecting ocular tissues, HSV can result in progressive scarring and visual impairment. Here, we report a case of herpetic keratitis reactivation in an immune-suppressed female undergoing carboplatin/paclitaxel therapy for high-grade ovarian adenocarcinoma. Few cases have linked chemotherapy with reactivation of HSV as herpetic keratitis. Treatment is available and can prevent permanent ocular damage if given early. Awareness and prompt diagnosis is imperative to maintaining ocular health.

\section{Case}

An 81 years old female was referred to the Gynecology/ Oncology clinic after visiting the Emergency Room for abdominal pain, bloating for 4 months, and increasing abdominal girth. A CAT scan revealed a $12.0 \times 11.3 \times 14.9 \mathrm{~cm}$ pelvic mass in the setting of as cites and an elevated cancer antigen 125 (CA125). The patient was diagnosed with a high-grade ovarian adenocarcinoma with a paracentesis of as cites fluid. Her medical course was complicated by alert lower extremity deep vein thrombosis with extensive bilateral pulmonary emboli. Thus, she was started on neoadjuvant chemotherapy with carboplatin and weekly paclitaxel. The patient also experienced a pneumothorax following the med port placement. She was an otherwise very active 81-year-old with a past medical history of hypertension, hypothyroidism, and cataracts.

After cycle 1 of carboplatin and weekly paclitaxel, the patient complained of left red eye and tearing during allergy season. Thought to be allergic conjunctivitis, she was given olopatadine hydrochloride $0.2 \%$ eye drops for daily use without symptomatic improvement. When she began experiencing left eye (OS) burning and pain, Optometry was promptly consulted. At the time of initial Optometric evaluation, the patient was experiencing left eye pain level of 9/10. Right eye (OD) visual acuity was 20/25 whereas OS was 20/50+. Bilateral pupils were equal, round, and reactive to light with extra ocular muscles smooth and 
intact. OS conjunctiva had graded 2 diffuse injections. The left cornea revealed a central herpetic ulcer measuring $2-3 \mathrm{~mm}$. She was prescribed ganciclovir ophthalmic gel five times daily with oral valacyclovir $500 \mathrm{mg}$ three times daily. A four-day follow up showed improvement in the conjunctive and corneal appearance. Refresh eye drops 4-6 times daily were prescribed. At her 12 day follow up, the patient was no longer symptomatic, and her OS vision improved to 20/30. A continued ganciclovir taper was ordered. On follow up day 19, the herpetic ulcer had resolved. She had transparent stromal corneal scarring in the area of the previous ulcer, but vision had returned to 20/20 OS.

\section{Comment}

The etiologies of an erythematous and irritated eye are numerous. Associated syndromes are wide-ranging and can be devastating. Quick diagnosis is both challenging and imperative. Benign conditions which should be considered include: blepharitis, conjunctivitis, corneal abrasion, foreign body, style and contact lens over wear. Urgent causes of eye erythematic include: angle closure glaucoma, hyphenate, hypoyon, iritic, infectious keratitis and sclerotic.

Here, we observed a case of eye erythematic that was herpetic in nature. In the United States, herpetic ocular infections have an annual incidence of 11.8 per 100,000 [1] and affect approximately 500,000 total people. Primary HSV infection occurs after direct inoculation of mucosa or skin. Clinical manifestation of a primary herpetic keratitis infection is rare, and when present, can mimic other processes such as conjunctivitis. More frequently, HSV ocular infections are a reactivation of latent herpes that is generally established in the trigeminal ganglia. After a dormant period, the virus proliferates, enters sensory neurons, and travels to the neuronal nuclei via retrograde transportation causing recurrent disease at the site of the initial infection [2]. While reactivation can be spontaneous, it can also be secondary to stress stimuli, UV light, changes in sex hormones, and immune suppression [2-4].

When reactivated, the sequelae can be devastating. Potential consequences include: ulcerations of the cornea, revascularization of the normally vascular corneal stoma, infiltration of leukocytes leading to corneal opacity and edema, stromal thinning and scarring, corneal perforation, damage to corneal nerves, non-healing corneal epithelial defects, secondary bacterial infection, necrotizing inflammation, and vision loss [5]. In fact, HSV keratitis is often considered the leading cause of infectious blindness in developed countries. Symptoms include pain, photophobia, blurred vision, tearing, itching, swelling, lid vesicles, and redness.

Early recognition and treatment is imperative to reduce long-term sequelae. If incorrectly diagnosed and topical glucocorticoid is applied without simultaneous antiviral medication, the infection can potentially worsen and extend into deeper structures [6]. Care should include early consult to optometric or ophthalmic specialists, and should involve visual acuity examination and anterior segment evaluation. Management may include combination oral antiviral therapy, and ophthalmic gel for symptomatic treatment as indicated, with frequent follow up. Ultimately, if one wants to reduce recurrences, the Herpetic Eye Study II (HEDS II) recommends suppressive prophylactic therapy of oral acyclovir 400mg twice daily. When used for a year, this regimen resulted in a $41 \%$ reduction in any ocular herpes recurrence and a $50 \%$ reduction in the recurrence of severe forms, such as disc form keratitis [7]. In some isolated episodes of herpetic keratitis, complete or nearcomplete resolution of symptoms and avoidance of permanent ocular defects can be achieved as seen in the current case.

A literature search revealed one case report of reactivation of latent herpes simplex virus with ocular infection, triggered by topical mitomycin $\mathrm{C}(\mathrm{MMC})$ therapy given for conjunctive squalors cell carcinoma (SCC). The patient was an immune-compromised individual taking weekly methotrexate and daily leflunomide for rheumatoid arthritis-associated nodular sclerotic. Right eye light sensitivity and redness prompted additional evaluation which revealed the SCC. Six weeks after initiation of the MMC treatment, the patient returned with complaints of right ocular irritation, intense pain, and redness, with subsequent diagnosis of herpetic keratitis. The patient was treated with cessation of MMC and initiation of trifluridine eye drops nine times daily. The patient had symptomatic improvement within one week [8]. Data regarding the association of herpetic keratitis reactivation secondary to systemic chemotherapy is sparse.

The current case describes an uncommon example of herpetic keratitis secondary to immune suppression with chemotherapy for which prompt diagnosis is imperative. As $90 \%$ of herpetic carriers are unaware that they are harboring the virus, providers must have a heightened awareness for this potential etiology. Knowing that it is a rare, but potential complication of chemotherapy will lead to a quicker diagnosis and decrease potential life altering consequences.

\section{Source of the Work}

Patient under care of the Womack Army Medical Center Gynecology Oncology Clinic.

\section{Disclosures}

These authors have no disclosures to provide, to include any funding received from the NIH, Wellcome Trust, and HHMI.

\section{Acknowledgement}

Thank you to Youykham Chanthavilay and Sharon Fitzgerald for your assistance with patient care and treatment. No financial support or manuscript preparation assistance was received.

\section{Presentation}

This manuscript was accepted for electronic poster presentation at the Armed Forces District Conference in San Antonio, TX in September 2017. 


\section{Precis}

Herpetic keratitis can arise during chemotherapy treatment and lead to significant vision loss. Prompt diagnosis and treatment are required to prevent serious long-lasting sequelae.

\section{References}

1. Young RC, Hodge DO, Liesegang TJ, Baratz KH (2010) Incidence, recurrence, and outcomes of herpes simplex virus eye disease in Olmsted County, Minnesota 1976-2007: the effect of oral antiviral prophylaxis. Arch Ophthalmol 128(9): 1178-1183.

2. Preston CM, Efstathiou S, Arvin A, Campadelli Fiume G, Mocarski E, et al. (2007) Molecular basis of HSV latency and reactivation.

3. Vicetti MR, Sheridan BS, Harvey SA, Schreiner RS, Hendricks RL, et al. (2010) 17-beta estradiol promotion of herpes simplex virus type 1 reactivation is estrogen receptor dependent. J Virol 84(1): 565-572.
4. Blyth WA, Hill TJ, Field HJ, Harbour DA (1976) Reactivation of herpes simplex virus infection by ultraviolet light and possible involvement of prostaglandins. J Gen Virol 33(3): 547-550.

5. Jones BR (1958) The clinical features of viral keratitis and a concept of their pathogenesis. Proc R Soc Med 51(11): 917-924.

6. Wilhelmus KR (1987) Diagnosis and management of herpes simplex stromal keratitis. Cornea 6(4): 286-291.

7. (2000) Oral acyclovir for herpes simplex virus eye disease: effect on prevention of epithelial keratitis and stromal keratitis. Herpetic Eye Disease Study Group Arch Ophthalmol 118(8): 1030-1036.

8. Siddique SS, Gonzalez Gonzalez LA, Amorese L, Shaikh M, Foster S, et al. (2010) Herpes keratitis in a patient undergoing treatment with topical mitomycin C. Cornea 30(4): 466-467.

Your next submission with Juniper Publishers will reach you the below assets

- Quality Editorial service

- Swift Peer Review

- Reprints availability

- E-prints Service

- Manuscript Podcast for convenient understanding

- Global attainment for your research

- Manuscript accessibility in different formats

( Pdf, E-pub, Full Text, Audio)

- Unceasing customer service

Track the below URL for one-step submission https://juniperpublishers.com/online-submission.php 